\title{
Estimation of microbiological contamination of maize seeds using isothermal calorimetry
}

\author{
Andrzej Skoczowski ${ }^{1}$ (1) Sebastian W. Przemieniecki ${ }^{2} \cdot$ Jakub Oliwa $^{3} \cdot$ Monika Kula-Maximenko $^{4} \cdot$ Magdalena Rys $^{4}$. \\ Iwona Stawoska ${ }^{1} \cdot$ Stanisław Karpiński ${ }^{5}$
}

Received: 3 July 2019 / Accepted: 29 June 2020 / Published online: 13 July 2020

(C) The Author(s) 2020

\begin{abstract}
The storage of maize seed intended for industrial purposes in foil silo bags is associated with microbiological contamination of the material by bacteria and fungi. This results in the loss of a part of the raw material or its deterioration and causes financial losses. In this paper, the relationship between the number of microorganisms colonizing maize seeds as well as changes in heat flow has been proved. For this purpose, the heat flow and total metabolic heat emission values (total heat) were analyzed. Calorimetric measurements of seed samples were made using the TAM III isothermal calorimeter. The seed samples with the same heat flow curves shape were homogenized, and microbial DNA was isolated from them. The quantitative real-time polymerase chain reaction (qPCR) was performed for detecting the main group of microorganisms colonizing maize seeds. It has been shown that in the case of seeds less affected by Bacillus and fungi (including yeast), the heat flow (in the range of 0-360 min) has a falling shape, while for more infected it grows almost linearly. The more infected maize seeds also show significantly higher values of total heat emission. The described research can be used to quickly assess the degree of seed contamination.
\end{abstract}

Keywords Bacillus spp. $\cdot$ Bacteria $\cdot$ Fungi $\cdot$ Heat flow $\cdot$ Zea mays

\section{Introduction}

Long-term storage of maize seeds (intended for example for the production of bioethanol) in plastic silo bags creates problems of technological and economic nature. Microbial

Andrzej Skoczowski

andrzej.skoczowski@up.krakow.pl

1 Institute of Biology, Pedagogical University of Cracow, Podchorążych 2, 30-084 Kraków, Poland

2 Department of Entomology Phytopathology and Molecular Diagnostics, University of Warmia and Mazury in Olsztyn, Prawocheńskiego 17, 10-720 Olsztyn, Poland

3 Department of Chemistry and Biochemistry, Institute of Basic Sciences, University of Physical Education, Jana Pawła II 78, 31-571 Kraków, Poland

4 The Franciszek Górski Institute of Plant Physiology Polish Academy of Sciences, Niezapominajek 21, 30-239 Kraków, Poland

5 Department of Plant Genetics, Breeding and Biotechnology, Warsaw University of Live Sciences, Nowoursynowska 159, 02-776 Warsaw, Poland contamination of the material by bacteria and fungi present on the seed coat negatively affects the fermentation processes and deterioration of the quality of the final product (e.g., presence of mycotoxins, ammonia, butyric acid). In addition, the reduction in the technological quality of seeds, and consequently the loss of a part of the raw material, causes significant financial losses. For this reason, monitoring the quality of the biological material taken is very important $[1,2]$.

Microbiological analysis of environmental samples based on microbial cultures (for example on Petri dishes) is timeconsuming and their results are often ambiguous. A better alternative is molecular methods such as: DNA markers, metagenomics analysis, DNA barcoding, molecular phylogenetic or using PCR. However, the disadvantage of methods based on DNA analysis is the inability to recognize live cells from dead ones as well as the variable efficiency of DNA extraction. An additional aspect is the need to design primers and probes and optimize the hybridization conditions [3, 4]. For this reason, we have decided to use isothermal calorimetry to monitor the degree of microbial contamination of seeds, without the need of long-term and expensive analysis. 
The isothermal calorimetry can be successfully used to monitor the growth of microorganism community [5]. Recently, isothermal calorimetry has been proposed as an effective method of quantitative and qualitative measurement of bacterial contamination of water [6]. In these studies, it was shown that the application of calorimetry allows to detect bacterial contamination much faster than the application of traditional culture of microorganisms on the medium. Calorimetry has also been used successfully in medical research to quickly analyze bacterial infections of blood [7, 8]. This method has been applied in the measurement of microbial activity and monitoring of toxicity and degradation of organic compounds in soil as well as in other environmental studies [9-12]. In turn, in the food industry, the kinetics of the process of fermentation and spoilage of plant tissues have been repeatedly examined using isothermal calorimetry [13].

Most of the physicochemical and biological processes involved in the metabolism of living organisms are accompanied by the generation of heat. It is therefore an unavoidable by product also in the process of microbiome development on plant material $[14,15]$. In addition, the formation of ordered spatial structures (related to the development of microorganism colonies) results in the release of Gibbs energy from the substrate, mainly as heat $[9,16]$. Thanks to the recording of the heat flow by means of a calorimeter, it is possible to monitor the development of microorganisms (such as bacteria, fungi and yeast) in real time, without interference the structure of the analyzed material and the course of biological processes [6]. It is worth noting that new, multi-channel calorimeters allow for very accurate measurements (with an accuracy of approx. $0.02{ }^{\circ} \mathrm{C}$ ) on many small samples at the same time and enable quantitative data interpretation, which makes calorimetry a good alternative to other microbiological analysis [9].

The aim of this experiment was to determine microbiological contamination of maize seeds based on the parameters describing heat production. For this purpose, the shape of heat flow curves and total metabolic heat emission values were analyzed as a function of microbiota abundance. After calorimetric measurements, the microbiome content on the seeds was determined based on the DNA amount of selected microorganism groups.

\section{Materials and methods}

\section{Plant material}

The research material was air-dry maize seeds (Zea mays L.), stored in foil silo bags on the area of the Ethanol Production Plant in Goświnowice (Poland). Samples for analysis were collected using a probe enabling average harvest of seeds over a length of $1.5 \mathrm{~m}$ of the silo bag.

\section{Calorimetric measurements}

The metabolic activity of maize seeds was measured at $20{ }^{\circ} \mathrm{C}$ in a TAM III isothermal calorimeter equipped with TAM Assistant Software (TA instruments, Lindon, US). The thermostat temperature was set to $20 \pm 10^{-6}{ }^{\circ} \mathrm{C}$. Seeds were stored before measurement in an air-conditioned room at $20{ }^{\circ} \mathrm{C}$. About $4 \mathrm{~g}$ of maize seeds were put into the stainlesssteel measuring ampoules of $4 \mathrm{~cm}^{3}$ capacity and tightly closed. The measurement was started $1 \mathrm{~h}$ after placing the sample in the calorimeter (full thermal stabilization of the sample). Then the heat flow in microwatts was recorded for $360 \mathrm{~min}$. The total emission of metabolic heat in the sample ( $\mathrm{mJ} \mathrm{g} \mathrm{g}_{\mathrm{DW}}^{-1}$ total heat) was obtained by integrating the surface under heat flow curve in a time interval of 0-360 min. The measurements were made on 18 seed samples from different silo bags. After calorimetric measurements, the samples were divided into two groups (9 samples each) according to the shape of heat flow curves. Within each group, the samples were combined at 3 and homogenized. As a consequence, the molecular analysis was made on 6 samples (3 for each group).

\section{Molecular microbiological analysis}

\section{DNA isolation}

DNA isolation was performed using the Soil DNA Purification Kit (EURx, Poland). Before isolation $10 \mathrm{~g}$ of maize seeds was grinding, next $100 \mathrm{mg}$ samples were transferred to 2-mL tubes containing glass beads and lysis buffer and then homogenized in a TissueLiser LT (Qiagen, Germany). Cell lysis was carried out for $5 \mathrm{~min}$ at maximum speed. Further steps were taken in accordance with the instructions attached to the isolation kit.

\section{Quantitative PCR}

In this paper, the real-time PCR was used to determine the load of microorganisms in the analyzed samples. The qPCR in Taqman technique to assess the load of bacteria, performed using BAC338F and BAC805R primers, and the BAC516F probe [17]. For bacteria of the genus, Lactobacillus were performed using F_alllact_IS and R_alllact_IS primers and the P_alllact_IS probe [18]. Amount of total fungi ITS number were performed using FungiQuant-F and FungiQuant-R primers set, and FungiQuant-Prb probe with method determined by Liu et al. [19]. Load of Pseudomonas spp. were determined by method described by Hu et al. [20] used $\mathrm{B} 2 \mathrm{BF}$ and $\mathrm{B} 2 \mathrm{BR} 3$ primers for phlD gene. 
For enumeration 16S rDNA copies gene for Bacillus spp. primers set 16SBACF and 16SBACR and method adapted from Mora et al. [21] were used. Reaction steps including: initial denaturation in $95^{\circ} \mathrm{C}$ for $10 \mathrm{~min}$ and 40 cycles $\left(95^{\circ} \mathrm{C}\right.$ for $15 \mathrm{~s}, 58{ }^{\circ} \mathrm{C}$ for $30 \mathrm{~s}, 72{ }^{\circ} \mathrm{C}$ for $50 \mathrm{~s}$ ), after reaction tested of thermal curve were performed. Final concentration of primers were $200 \mathrm{nM}$.

Determination of the number of toxins-producing fungi of Fusarium, Penicillium and Aspergillus genera were performed with Tri5 forward and Tri5 reverse primers and probe for Tri5, rRNA forward, rRNA reverse primers and probe for rRNA and Pks forward Pks reverse and probe for Pks, respectively, in multiplex reaction. Method was performed according Vegi and Wolf-Hall [22]. Yeast were determined using qPCR in Sybr Green technique with YEASTF and YEASTR primers set and reaction was performed according to [23].

Appropriate amplicons of Bacillus subtilis, Pseudomonas putida, Fusarium culmorum, Penicillium chrysogenum and Aspergillus niger were ligated with plasmids (TOPO $^{\mathrm{TM}}$ TA Cloning ${ }^{\mathrm{TM}} \mathrm{Kit}$, with pCR $^{\mathrm{TM}}$ 2.1-TOPO ${ }^{\mathrm{TM}}$, Thermo Fisher Scientific) and served as standards for their respective domains. All reaction performed in volume $20 \mu \mathrm{L}$ per sample, using a Maxima (Probe or SybrGreen) qPCR Master Mix 2x (Thermo Fisher Scientific, USA). The PCR efficiency of the reactions was between 0.96 and $1.01\left(R^{2}\right.$ between 0.991 and 1). Estimation of gene copies was performed in "DNA Copy Number and Dilution Calculator" (ThermoFisher Scientific, https://www.thermofisher.com/pl/ en/home/brands/thermo-scientific/molecular-biology/molec ular-biology-learning-center/molecular-biology-resourcelibrary/thermo-scientific-web-tools/dna-copy-number-calcu lator.html).

\section{Statistical analysis}

The results of the microbiome content were analyzed in the Statistica 12 program (Statsoft, Poland) using the one-way analysis of variance (ANOVA) and the Duncan's post hoc test at the significance level of $p \leq 0.05$. In addition, principal component analysis (PCA) with Pearson's correlation was performed, which shows the relationship between parameters (XLSTAT, Addinsoft, United States).

\section{Results}

Molecular methods based on DNA analysis are more reliable than classical methods (culture on microbiological media) because the counting of microorganism cells is done by counting marker (conserved) genes present in almost every microorganism cell. A pair of primers, i.e., short host complement sequences, is used for this. Primers can be complementary to sequences at different taxonomic levels, which makes it possible to determine the overall charge of microorganisms or selected species and even pathogenic strains.

Molecular analysis allowed to distinguish samples with lower (LMC) and higher (HMC) microbiome content. Based on statistical results, it was found that number of gene copies of Bacillus ssp. and total fungi for LMC samples were significantly lower than HMC samples set (Table 1). For example, content of Bacillus spp. was 12-fold higher in HMC than in LMC samples.

It has been shown that in the case of LMC the heat flow curves (in the range of 0-360 min) has a falling shape, i.e., for maize seeds less affected by Bacillus and fungi. The heat flow reached its maximum on average after about 90 min and then decreased. On the other hand, for HMC seeds heat flow curve grows almost linearly (Fig. 1). Moreover, the HMC seeds also show significantly higher total heat values (Fig. 1-insert).

The variability of biplot axes $F 1$ and $F 2$ in PCA was $70 \%$. The dominant mass of variability reached $F 1$ axis. The similarity of the HCM sample results was high; therefore, their location on the biplot was close to each other and coordinated in one quadrant (positively to the $F 1$ and $F 2$ axes). In general, the similarity of the LMC1 and LMC2 results was similar to each other and the coordination for the axes of both samples was negative for $F 1$ and positive for $F 2$, while the LMC3 sample was negatively coordinated for both axes. This indicates that part of the LMC3 results were partly different from the other LMCs but were still clearly different from HCM samples. Detailed PCA results have shown correlation $(r>0.9)$ between total heat value and Bacillus spp. content and average correlation with total fungi and yeast content (Fig. 2). However, these values (especially Bacillus spp. content and total heat) were high for all HMC samples, and generally low for LMC samples. It was also observed that the contents of total bacteria, Lactobacillus spp. and Fusarium were positively correlated with each other. The content of these groups of microorganisms was high in the LMC1 and LMC2 samples, but not in the LMC3 sample, which may indicate the influence of other factors on the obtained calorimetric parameters (Fig. 2). The content of Pseudomonas spp., and toxicogenic Penicillium spp. and Aspergillus spp. was below the limit of quantification $(\sim 50$ gene copies).

\section{Discussion}

Comparison of the number of microorganisms (determined based on qPCR analysis) colonizing seeds with the efficiency of heat production proves that the shape of the heat flow curves depends on the amount and metabolic activity 


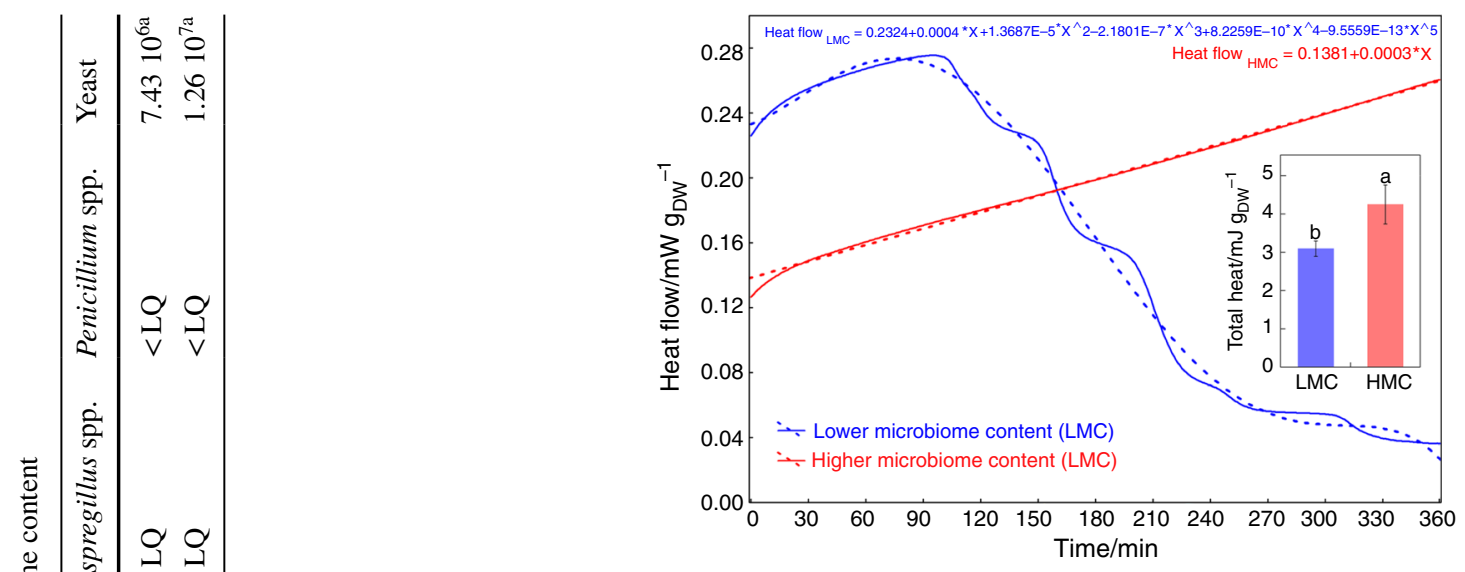

Fig. 1 The specific heat flow curves and total metabolic heat emission values (total heat-insert) of maize seeds with varying degrees of microbial contamination. Solid lines - the average value for 9 independent measurements for each line, dotted lines-fit curves, LMClower microbiome content, HMC-higher microbiome content

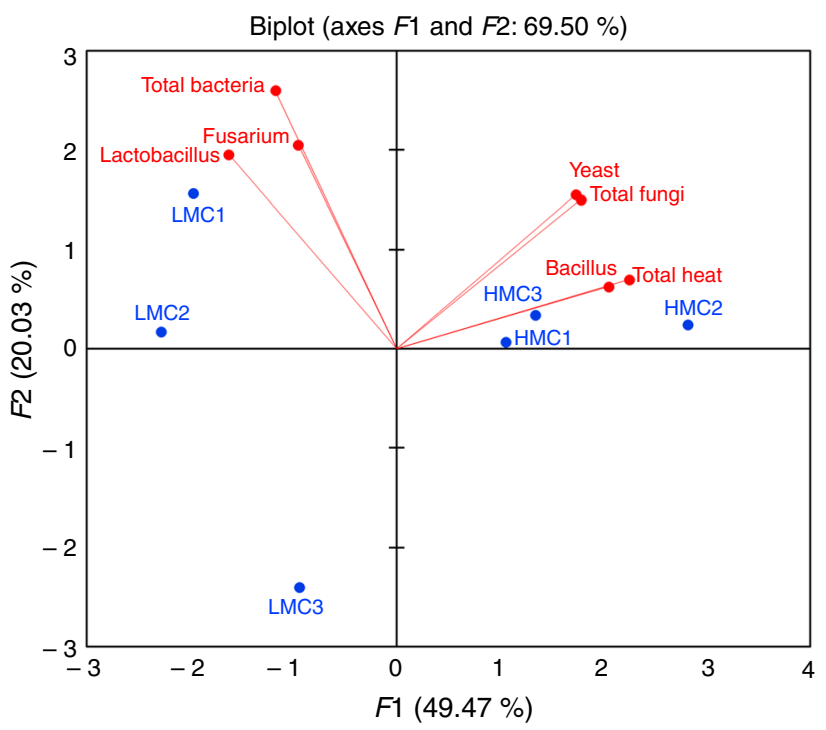

Fig. 2 Principal component analysis (PCA) of the bacterial communities colonizing maize seeds for lower microbiome content LMC and higher microbiome content HMC. LMC $(1,2,3)$ and HMC $(1,2,3)$ means individual replications for LMC and HMC samples

of the microbial community $[14,15]$. The high total heat values in samples with a high microbiome content (mainly fungi and Bacillus spp.) are confirmed by experiments carried out on perishable food products, in which the development of microorganisms was accompanied by a heat flow increase $[14,24]$. In these and other cases, the qualitative microbial analysis was not performed; however, the use of microbial growth inhibitors resulted in a decrease in total heat of samples. Similar conclusions can be drawn from analysis of sediments of water reservoirs 
rich in anaerobic and aerobic microorganisms [25]. In this case, the non-specificity of the calorimetric method consists in the difficulty in distinguishing the metabolic heat of microorganisms from the heat of chemical reactions. A similar problem was observed in the experiment regarding the deterioration of moist tobacco products [26]. However, air-dry seeds are characterized by low metabolic activity. Also, during the quantitative determination of soil microorganisms, it was confirmed that the number of living cells of bacteria and fungi was strongly correlated with the recorded amount of heat [27]. It was proved that the increasing density of microorganisms in the soil resulted in a decrease in the heat production [12]. The low content of the microbiome in the sample makes the food base of microorganisms big. Therefore, as the time goes on, a rapid growth of microorganisms may take place. This would explain the visible falling shape of heat flow curves. At the same time, in samples with high microbiome content, the opposite trend was observed, suggesting a decrease in the number of living cells of microorganisms, and thus an increase in their metabolic activity. However, this hypothesis should be verified in further studies.

The results of this investigation clearly pointed out a longer activity of microbiota metabolism in samples with a high content of fungi (including yeast) and sporulating bacteria of the genus Bacillus spp. Mentioned process indicates the activity associated with the slow growth of spores Bacillus spp. on maize and utilization of nutrients such as starch or other high energy compounds. This phenomenon is very dynamic during the aerobic spoilage of silage. The quality of maize seeds after breaking anaerobic conditions undergoes some modifications conducted to deterioration of plant material. Qualitative changes mainly concern: the increase in the concentration of starch, consumption by aerobic microorganisms of volatile acids (mainly lactic acid, acetic acid and their formulas) as well as ethanol and their volatilization. In recent years, bacteria of the genus Bacillus or other spores and molds that are the main factor in the oxidative deterioration of maize silage are increasingly identified, which is associated with dynamic changes in heat release [28-30].

After additional tests on microbiological cultures on appropriate media (data not shown), it was possible to determine that despite the high number of gene copies (data from qPCR), the weak activity of molds and yeasts in all analyzed samples, with a large number of active sporulating bacteria was observed. This indicates a high content of these microorganisms in the earlier period (transport, storage or discontinuation of anaerobic conditions), which may explain the release of nutrients and the rapid development of the digestive bacteria responsible for heating and oxygen-based substrate deterioration.

\section{Conclusions}

In conclusion, the analysis of heat flow curves after $360 \mathrm{~min}$ measurements (and even after $180 \mathrm{~min}$ ) allows to determine the degree of biological material contamination by bacteria Bacillus spp. and mold fungi. Isothermal calorimetry is therefore a promising method that can be used to quickly assess the degree of microbial infection of plant material, e.g., seeds. However, in vitro analysis with controlled inoculation of undesirable microorganisms is needed to initial establish calorimetric curves for key groups of microorganisms deteriorating the quality of plant material.

Acknowledgements This work was founded by the National Centre for Research and Development, Grant BIOSTRATEG-2 298241/10/ NCBR/2016, acronym CROPTECH.

Open Access This article is licensed under a Creative Commons Attribution 4.0 International License, which permits use, sharing, adaptation, distribution and reproduction in any medium or format, as long as you give appropriate credit to the original author(s) and the source, provide a link to the Creative Commons licence, and indicate if changes were made. The images or other third party material in this article are included in the article's Creative Commons licence, unless indicated otherwise in a credit line to the material. If material is not included in the article's Creative Commons licence and your intended use is not permitted by statutory regulation or exceeds the permitted use, you will need to obtain permission directly from the copyright holder. To view a copy of this licence, visit http://creativecommons.org/licenses/by/4.0/.

\section{References}

1. Alonso VA, Pereyra CM, Keller LA, Dalcero AM, Rosa CA, Chiacchiera SM, Cavaglieri LR. Fungi and mycotoxins in silage: an overview. Appl Microbiol. 2013;115(3):637-43. https://doi. org/10.1111/jam.12178.

2. Fijałkowska M, Pysera B, Lipiński K, Strusińska D. Changes of nitrogen compounds during ensiling of high protein herbagesa review. Ann Anim Sci. 2015;15(2):289-305. https://doi. org/10.1515/aoas-2015-0008.

3. Nagarajan K, Loh KC. Molecular biology-based methods for quantification of bacteria in mixed culture: perspectives and limitations. Appl Microbiol Biotechnol. 2014;98:6907-19. https://doi. org/10.1007/s00253-014-5870-9.

4. Bouchez T, Blieux AL, Dequiedt S, Domaizon I, Dufresne A, Ferreira S, et al. Molecular microbiology methods for environmental diagnosis. Environ Chem Lett. 2016;14:423-41. https:// doi.org/10.1007/s10311-016-0581-.

5. Fessas D, Schiraldi A. Isothermal calorimetry and microbial growth: beyond modeling. J Therm Anal Calorim. 2017;130(1):567-72. https://doi.org/10.1007/s10973-017-6515-x.

6. Maskow T, Wolf K, Kunzec W, Endersb S, Harmsa H. Rapid analysis of bacterial contamination of tap water using isothermal calorimetry. Thermochim Acta. 2012;543:273-80. https://doi. org/10.1016/j.tca.2012.06.002.

7. Trampuz A, Salzmann S, Antheaume J, Daniels AU. Microcalorimetry: a novel method for detection of microbial contamination in platelet products. Transfusion. 2007;47(9):1643-50. https://doi. org/10.1111/j.1537-2995.2007.01336.x. 
8. Braissant O, Wirz D, Göpfert B, Daniels AU. Biomedical use of isothermal microcalorimeters. Sensors. 2010;10(10):9369-83. https://doi.org/10.3390/s101009369.

9. Braissant O, Wirz D, Göpfert B, Daniels AU. Use of isothermal microcalorimetry to monitor microbial activities. FEMS Microbiol Lett. 2010;303(1):1-8. https://doi.org/10.111 1/j.1574-6968.2009.01819.x.

10. Maskow T, Paufler S. What does calorimetry and thermodynamics of living cells tell us? Methods. 2015;76(1):3-10. https://doi. org/10.1016/j.ymeth.2014.10.035.

11. Rong XM, Huang QY, Jiang DH, Cai P, Liang W. Isothermal microcalorimetry: a review of applications in soil and environmental sciences. Pedosphere. 2007. https://doi.org/10.1016/S1002 -0160(07)60019-8.

12. Barros N, Feijóo S, Fernández S. Microcalorimetric determination of the cell specific heat rate in soils: relationship with the soil microbial population and biophysic significance. Thermochim Acta. 2003. https://doi.org/10.1016/S0040-6031(03)00255-7.

13. Wadsö L, Galindo FG. Isothermal calorimetry for biological applications in food science and technology. Food Control. 2009. https ://doi.org/10.1016/j.foodcont.2008.11.008.

14. Wadsö I. Isothermal microcalorimetry near ambient temperature: an overview and discussion. Thermochim Acta. 1997. https://doi. org/10.1016/S0040-6031(96)03136-X.

15. Gustaffson L. Microbiological calorimetry. Thermochim Acta. 1991. https://doi.org/10.1016/0040-6031(91)80181-H.

16. Stockar U, Maskow T, Liu J, Marison I, Patino R. Thermodynamics of microbial growth and metabolism: an analysis of the current situation. J Biotechnol. 2006. https://doi.org/10.1016/j.jbiot ec.2005.08.012

17. Yu Y, Lee C, Kim J, Hwang S. Group-specific primer and probe sets to detect methanogenic communities using quantitative realtime polymerase chain reaction. Biotechnol Bioeng. 2005. https ://doi.org/10.1002/bit.20347.

18. Haarman M, Knol J. Quantitative real-time PCR analysis of fecal Lactobacillus species in infants receiving a prebiotic infant formula. Appl Environ Microbiol. 2006. https://doi.org/10.1128/ AEM.72.4.2359-2365.2006.

19. Liu CM, Kachur S, Dwan MG, Abraham AG, et al. FungiQuant: a broad-coverage fungal quantitative real-time PCR assay. BMC Microbiol. 2012. https://doi.org/10.1186/1471-2180-12-255.

20. Hu J, Wei Z, Friman VP, Gu SH, Wang XF, Eisenhauer N, et al. Probiotic diversity enhances rhizosphere microbiome function and plant disease suppression. MBio. 2016;7(6):1-8.

21. Mora I, Cabrefiga J, Montesinos E. Antimicrobial peptide genes in Bacillus strains from plant environments. Int Microbiol. 2011. https://doi.org/10.2436/20.1501.01.151.
22. Vegi A, Wolf-Hall CE. Multiplex real-time PCR method for detection and quantification of mycotoxigenic fungi belonging to three different genera. J Food Sci. 2013. https://doi.org/10.111 1/j.1750-3841.2012.03008.x.

23. Hierro N, Esteve-Zarzoso B, Gonzalez A, Mas A, Guillamon JM. Real-time quantitative PCR (QPCR) and reverse transcriptionQPCR for detection and enumeration of total yeasts in wine. Appl Environ Microbiol. 2006. https://doi.org/10.1128/aem.00388-06.

24. Alyabyev A, Gordon L, Loseva NL, Rachimova G, Tribunskih V, Estrina R, et al. The effect of a natural inhibitor isolated from the tealeaf on the energy processes in model systems. Thermochim Acta. 2004. https://doi.org/10.1016/j.tca.2004.07.024.

25. Haglund AL, Lantz P, Törnblom E, Tranvik L. Depth distribution of active bacteria and bacterial activity in lake sediment. FEMS Microbiol Ecol. 2003. https://doi.org/10.1016/S0168 -6496(03)00190-9.

26. Almqvist SO, Karlson Dunas L. Microcalorimetry: a useful tool for solving shelf life problems in the food industry. In: TA instruments microcalorimetry compendium vol II. TA instruments; 2008. pp. 66-70.

27. Critter SAM, Freitas SS, Airoldi C. Comparison between microorganism counting and a calorimetric method applied to tropical soils. Thermochim Acta. 2002. https://doi.org/10.1016/S0040 -6031(02)00246-0.

28. Gerlach K, Weiß K, Roß F, Büscher W, Südekum K-H. Changes in maize silage fermentation products during aerobic deterioration and its impact on feed intake by goats. Proc XVI th Int Silage Conf. 2012. https://doi.org/10.23986/afsci.6739.

29. Borreani G, Dolci P, Tabacco E, Cocolin L. Aerobic deterioration stimulates outgrowth of spore-forming Paenibacillus in corn silage stored under oxygen-barrier or polyethylene films. J Dairy Sci. 2013. https://doi.org/10.3168/jds.2013-6649.

30. Wang TN, Wei H, Mingli Z, Chuncheng X. Dynamics associated with prolonged ensiling and aerobic deterioration of total mixed ration silage containing whole crop corn. Asian Australas J Anim Sci. 2016. https://doi.org/10.5713/ajas.15.0319.

Publisher's Note Springer Nature remains neutral with regard to jurisdictional claims in published maps and institutional affiliations. 